\title{
Species can base their impression of themselves on the number of sensory neurons they have and their IUCN level
}

aaron goetz ( $\square$ aarongoetz2020@gmail.com )

na https://orcid.org/0000-0002-0674-8752

Article

Keywords:

Posted Date: October 21st, 2021

DOl: https://doi.org/10.21203/rs.3.rs-993231/v1

License: (c) (i) This work is licensed under a Creative Commons Attribution 4.0 International License.

Read Full License 


\section{Abstract}

Humans have the most sensory neurons of any terrestrial species, $18.83 \mathrm{~B}$, with more than twice as many as the runner up western gorilla. There are three aquatic species with more than humans and seven more with more than the western gorilla. The killer whale with more than twice as many as humans, long-finned and short-finned pilot whale with a little less than twice humans. With that many sensory neurons it would be assumed that those would be the species with the most emotional disturbance from anthropogenic influence. There is no data on killer whale endangerment, and both long and short finned pilot whales are LC, ranking them 23rd and 24th most disturbed species. It is important for us to consider what the species means to them in evaluating what species we should care about, it would be beneficial to base that on what species care about themselves the most.

\section{Introduction}

Humans have the most sensory neurons of any terrestrial species, 18.83B, with more than twice as many as the runner up western gorilla. There are three aquatic species with more than humans and seven more with more than the western gorilla. The killer whale with more than twice as many as humans, long-finned and short-finned pilot whale with a little less than twice humans. With that many sensory neurons it would be assumed that those would be the species with the most emotional disturbance from anthropogenic influence. There is no data on killer whale endangerment, and both long and short finned pilot whales are LC, ranking them 23rd and 24th most disturbed species.

\section{Methods}

Species sensory associated neuron and total neuron quantities from wiki were columnized on an excel. There are 146 species that have their sensory neuron quantities documented on wiki and 110 of those have their total quantities on wiki. A percentage of sensory neurons was then calculated for each of the 110 species that have both. The 146 species were checked on the IUCN for their level. 26 species are without IUCN document so 120 species have both sensory neuron quantities and an IUCN level. For an IUCN level .01 was used for LC, .25 for NT, .5 for VU, .75 for EN and .99 for CR. That percentage multiplied by the quantity of sensory neurons totals a level of IUCN sense for each of the 120 species. Each of the 120 species levels of IUCN sensory use was percentagized comparatively to the species with the most combined sensory neurons and IUCN level. A weighted level of IUCN sense was also calculated for the 110 species that have both sensory and total neuron quantities, only 92 of those with an IUCN level, multiplying the IUCN level and the percentage of sensory neurons to total.

These variables were then put into $\mathrm{R}$ as a MLR using $y_{\mathrm{i}}=\beta_{0}+\beta_{1}+\beta_{2 \ldots} \beta_{i}+\epsilon_{l,} \epsilon_{i} \sim \operatorname{Normal}\left(0, \sigma^{2}\right)$ to determine the role of each of the columns as variables with the response being the total level of IUCN sense. $y=$ total.level. of.iucn.sense

sens= sensory.associated.neurons 
tot $=$ total.neurons

perc $=$ percentage. sens

iucn= iucn.level

name $=$ name

weightediucn= weighted.level.of.iucn.sense

AIC scores were compared for $\mathrm{y}_{1} \sim$ sens + perc + iucn, $\mathrm{y}_{2} \sim$ perc + iucn + weightediucn, $\mathrm{y}_{3} \sim 1(\mathrm{null}), \mathrm{y}_{4} \sim$ iucn+ sens + weightediucn, $\mathrm{y}_{5} \sim$ weightediucn + tot + iucn, and $\mathrm{y}_{6} \sim$ sens + iucn.

\section{Results}

The three species with more sensory neurons than humans have not had their total neurons quantified, so humans have the most total neurons of all neural measured species with, 86B total, while the western gorilla has 33.4B and the orangutan 32.6B. Five of the 146 species that have sensory neuron totals are CR with the IUCN an eight are EN. Of the 14 species with the most disturbed ranked (having the most neurons combined with IUCN level), 5 are VU, 6 EN and 3 CR. The species with the most disturbed rank is an EN, the blue whale. After the ninth ranked species the percent of IUCN sense goes less than half of the top ranked species.

Table 1: Top 28 most disturbed species IUCN sense = sensory associated neurons $\mathrm{x}$ IUCN level

\begin{tabular}{|c|c|c|c|c|c|c|c|c|}
\hline 1 & name & sensory associated neurons & total neurons & percentage sens & iucn level & weighted level of iucn sens & f iucn sense & percent of sense \\
\hline 2 & Blue whale & $15,000,000,000$ & & & 0.75 & & 11250000000 & 1 \\
\hline 3 & Western gorilla & $9,100,000,000$ & 33400000000 & 0.27245509 & 0.99 & 0.269730539 & 9009000000 & 0.8008 \\
\hline 4 & Orangutan & $8,300,000,000$ & 32600000000 & 0.254601227 & 0.99 & 0.252055215 & 8217000000 & 0.7304 \\
\hline 5 & Fin whale & $15,000,000,000$ & & & 0.5 & & 7500000000 & 0.666666667 \\
\hline 6 & Chimpanzee & $7,400,000,000$ & 28000000000 & 0.264285714 & 0.75 & 0.198214286 & 5550000000 & 0.493333333 \\
\hline 7 & African elephant & $5,600,000,000$ & & & 0.99 & & 5544000000 & 0.4928 \\
\hline 8 & Pygmy chimpanzee or bonobo & $7,250,000,000$ & & & 0.75 & & 5437500000 & 0.483333333 \\
\hline 9 & Asian elephant & $6,775,000,000$ & $2.57 E+11$ & 0.026361868 & 0.75 & 0.019771401 & 5081250000 & 0.451666667 \\
\hline 10 & Walrus & $3,929,000,000$ & & & 0.5 & & 1964500000 & 0.174622222 \\
\hline 11 & Guenon & $2,500,000,000$ & & & 0.75 & & 1875000000 & 0.166666667 \\
\hline 12 & Mandrill & $3,102,000,000$ & & & 0.5 & & 1551000000 & 0.137866667 \\
\hline 13 & Hyacinth macaw & $2,944,000,000$ & & & 0.5 & & 1472000000 & 0.130844444 \\
\hline 14 & Pigtail Macaque & $2.531,000,000$ & & & 0.5 & & 1265500000 & 0.112488889 \\
\hline 15 & Kea & $1,281,000,000$ & 2149000000 & 0.596091205 & 0.75 & 0.447068404 & 960750000 & 0.0854 \\
\hline 16 & Horse & $1,200,000,000$ & & & 0.75 & & 900000000 & 0.08 \\
\hline 17 & Giraffe & $1,731,000,000$ & 10750000000 & 0.161023256 & 0.5 & 0.080511628 & 865500000 & 0.076933333 \\
\hline 18 & Tufted capuchin & $1,140,000,000$ & 3691000000 & 0.308859388 & 0.75 & 0.231644541 & 855000000 & 0.076 \\
\hline 19 & Bonnet macaque & $1,660,000,000$ & 3780000000 & 0.439153439 & 0.5 & 0.21957672 & 830000000 & 0.073777778 \\
\hline 20 & Grey parrot & $850,000,000$ & 1566000000 & 0.542784163 & 0.75 & 0.407088123 & 637500000 & 0.056666667 \\
\hline 21 & Raccoon & $453,000,000$ & 2148000000 & 0.210893855 & 0.99 & 0.208784916 & 448470000 & 0.039864 \\
\hline 22 & Crab-eating macaque & $800,960,000$ & 3440000000 & 0.232837209 & 0.5 & 0.116418605 & 400480000 & 0.035598222 \\
\hline 23 & Long-finned pilot whale & $37,200,000,000$ & & & 0.01 & & 372000000 & 0.033066667 \\
\hline 24 & Short-finned pilot whale & $35,000,000,000$ & & & 0.01 & & 350000000 & 0.031111111 \\
\hline 25 & Tarsius & $310,000,000$ & & & 0.99 & & 306900000 & 0.02728 \\
\hline 26 & Lion & $545,240,000$ & 4667000000 & 0.116828798 & 0.5 & 0.058414399 & 272620000 & 0.024232889 \\
\hline 27 & Risso's dolphin & $18,750,000,000$ & & & 0.01 & & 187500000 & 0.016666667 \\
\hline 28 & Goeldi's marmoset & $357,130,000$ & $636,000,000$ & 0.561525157 & 0.5 & 0.280762579 & 178565000 & 0.015872444 \\
\hline
\end{tabular}


The results from the AIC scores $\mathrm{y}_{1}-\mathrm{y}_{6}$ have $\mathrm{y}_{4}$ with the best covariates, with $\mathrm{y}_{1}$ only 45.11795 away (the others are more than 5,000 away). This shows that combining the iucn and the sens variables are most effective in the 3 variable equations.

Table 2: $€_{4} \sim \operatorname{Normal}\left(0, \sigma^{2}\right)$

Residual standard error: $8.334 \mathrm{e}-07$ on 8 degrees of freedom

( 55 observations deleted due to missingness)

Multiple R-squared:

1, Adjusted R-squared: 1

$1 \mathrm{~m}($ formula $=y \sim$ iucn + sens + weightediucn $)$

Residuals:

$\begin{array}{rrrr}\text { Min } & 1 Q & \text { Median } & 3 Q \\ -1.574 \mathrm{e}-06 & 0.000 \mathrm{e}+00 & 0.000 \mathrm{e}+00 & 0.000 \mathrm{e}+00\end{array}$

$1.574 \mathrm{e}-06$

$\begin{array}{lrrr}\text { (Intercept) } & \text { Estimate Std. Error } & t \text { value } \\ \text { iucn } & 1.118 \mathrm{e}+07 & 1.664 \mathrm{e}-06 & 6.719 \mathrm{e}+12\end{array}$

$\begin{array}{lllll}\text { iucn } & 1.118 \mathrm{e}+07 & 1.664 \mathrm{e}-06 & 6.719 \mathrm{e}+12 \\ & 1.700 \mathrm{e}+07 & 7.943 \mathrm{e}-05 & 2.140 \mathrm{e}+11\end{array}$

\section{Discussion}

It is important for us to consider what the species means to them in evaluating what species we should care about, it would be beneficial to base that on what species care about themselves the most.

\section{Supplementary Files}

This is a list of supplementary files associated with this preprint. Click to download.

- project.csv

- project.txt 